\title{
Rising trend of life expectancy in Shanghai, China: quantitative analysis of changes by mortalities in different age groups and specific diseases
}

\author{
Huiting $\mathrm{Yu}^{1}$, Ming $\mathrm{Han}^{1}$, Wenzheng Jin ${ }^{1}$, Qing Yang ${ }^{1}$, Renzhi Cai ${ }^{1}$, Naisi Qian ${ }^{1}$, Jiajie Zang ${ }^{2}$, Wang Chunfang*1 \\ ${ }^{1}$ Department of vital statistics, Shanghai Municipal Center for Disease Control and Prevention, Shanghai, China \\ ${ }^{2}$ Department of nutrition hygiene, Shanghai Municipal Center for Disease Control and Prevention, Shanghai, China
}

Received: June 16, 2015

DOI: $10.5430 /$ jer.v1n1p37
Accepted: July 30, 2015

Online Published: August 14, 2015

\begin{abstract}
Objective: Life expectancy had increased from 73.16 to 79.82 years in men and 77.74 to 84.44 years in women during 1990-2010 in Shanghai. The elevating rate was faster than that of most developed countries. This study is to access life expectancy increased in Shanghai by different age groups and specific diseases.

Methods: Arriaga's decomposition methods were applied to life tables and mortality data (1990-2010) to estimate changes in life expectancy.

Results: The largest contributions lied on elderly population (60 years old \& above) (4.79-year in men and 4.90-year in women). During 1990-2000, reductions in mortality of respiratory system diseases, especially in chronic obstructive pulmonary disease (COPD), contributed 1.36-year increase in men and 1.16-year increase in women. During 2000-2010, reductions in mortality of circulatory system diseases, especially in cerebrovascular disease (CVD), contributed 0.82-year increase in men and 1.08-year increase in women.

Conclusions: Rapid increases in life expectancy were mostly achieved by declining mortality in aged population and chronic noncommunicable diseases (CND), nevertheless CND were still the main causes of death in Shanghai, which implicated that the prevention strategies for chronic diseases was effective and should be persevered for a long time in the future.
\end{abstract}

Key Words: Life expectancy, Cerebrovascular disease, Chronic obstructive pulmonary disease

\section{INTRODUCTION}

Life expectancy at birth (LE) had increased steady in most developed countries in the early $20^{\text {th }}$ century. ${ }^{[1,2]}$ Associating with rapid economic growth in 1990s, Shanghai as one of the developed cities in China, had got a huge process in human longevity. In order to discern further potential trends of LE, it is important to detect factors that affected LE. However, LE would be affected by many complicated factors, and until now the affections from different age groups or diseases had not been declared clearly in China. Quantification of contributions from each age group and disease to increases of LE in Shanghai can not only explain the reasons of longevity in some countries or areas, but also give hints for the future increase of LE in areas in China, even other Asian countries where were in low LE. So the purpose of this study is to access increases of LE in the past two decades in Shanghai

\footnotetext{
*Correspondence: Wang Chunfang; Email: htyu_D@126.com; Address: Department of vital statistics, Shanghai Municipal Center for Disease Control and Prevention, Shanghai 200336, China.
} 
by age groups and diseases.

\section{MethodS}

\subsection{Data}

Life tables and mortality data were obtained from death registry system in Shanghai Municipal Center for Disease Control and Prevention (SCDC). The death registry system in Shanghai was implemented in 1951, and had been computerized since 1990. The information on death certificates was recommended by World Health Organization. For both of domestic and hospital deaths, physicians completed death certificates, with information on demographics, date of death and cause of death, coding according International Classification of Diseases versions 9 (ICD-9) before 1989 and ICD-10 for 1990 through 2010. Conversion table published by the World Health Organization was defined to transfer all examined diseases to ICD-10.

\subsection{Statistical analysis}

LE for males and females in 1990, 2000 and 2010 were calculated with standard demographic techniques. Contributions of each age group and specific cause of death to the changes of LE were estimated with the Arriaga's decomposition method. ${ }^{[3,4]}$ This method decomposed the contributions which were owed to the declined mortality rate in each age group during the given period into 3 parts: a direct effect, and an indirect and interaction effect. The contributions in a particular age group can also be decomposed by diseases, and reductions in mortality from a specific cause will increase LE and diseases with increased mortality will let LE decrease.

\section{RESULTS}

During 1990-2000, LE of Shanghai was 10 years more than the world average level and equal to that of the high income country (see Figure 1). Until 2010, it reached 82.13 years, almost 2-year higher than that of the high income country. During 2000-2010, the growth rate had exceeded that of Japan in 1990-2000 (LE of Japan in 1990 and LE of Shanghai in 2000 were in the same level), and the rapid growth rate was similar to Hong Kong during 1990-2000.

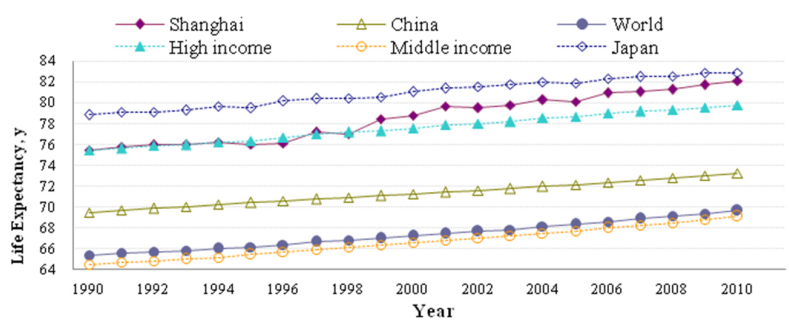

Data source: World Bank WDI Database.

Figure 1. Life expectancy at birth in Shanghai compared with world level, 1990-2010

\subsection{Contributions of specific age groups}

LE had increased 6.7-year both in men and in women during 1990-2010. In the first decade, a remarkable reduction in infant mortality accounted for $14.7 \%$ (0.55-year) increase to male LE. But during 2000-2010, infant mortality rate was stable and almost didn't contribute to the increase of LE. For females, the reduction in infant mortality increased LE by 0.50 -year (7.24\%) during 1990-2010 and 0.13-year in 2000-2010. Considering the cumulative contributions, most contributions came from elderly population (60 years old \& above), accounting for 4.79-year in men and 4.90-year in women (see Figure 2).

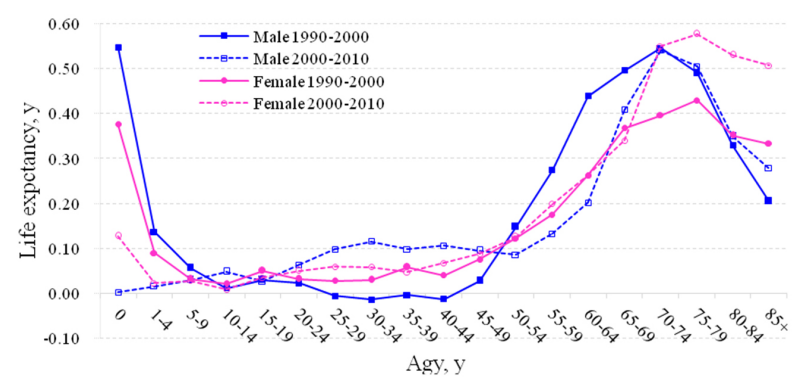

Figure 2. Age group-specific contributions to life expectancy increases among males and females: Shanghai, 1990-2000 and 2000-2010

\subsection{Contributions by disease groups}

The most prominent diseases for the increases of LE were respiratory system diseases (J00-J98), circulatory system diseases (I00-I99), cancers (C00-D48) and external causes of death (C01-Y89). Figure 3 showed that the contributions from respiratory system diseases were downward in both genders. And the contributions from cancers were downward in men and upward in women. Contributions from circulatory system diseases and external causes of death were increase in both genders.

Reductions in mortalities of respiratory system diseases contributed 1.36-year and 0.76-year increase to male LE in 19902000 and 2000-2010 respectively. Circulatory system diseases which were more important to women, contributed 0.78-year and 1.08-year increase in female LE in the two decades respectively. Cancers also made positive contributions in LE increase, but increases were much more in men than in women.

Other diseases, such as infectious diseases, mental and behavioral disorders, digestive system diseases, genitourinary system diseases, congenital malformations and perinatal death also made positive contributions to LE. On the other hand, these positive contributions were counteracted by the increased mortality in endocrine, nutritional, and metabolic 
diseases and nervous systems.

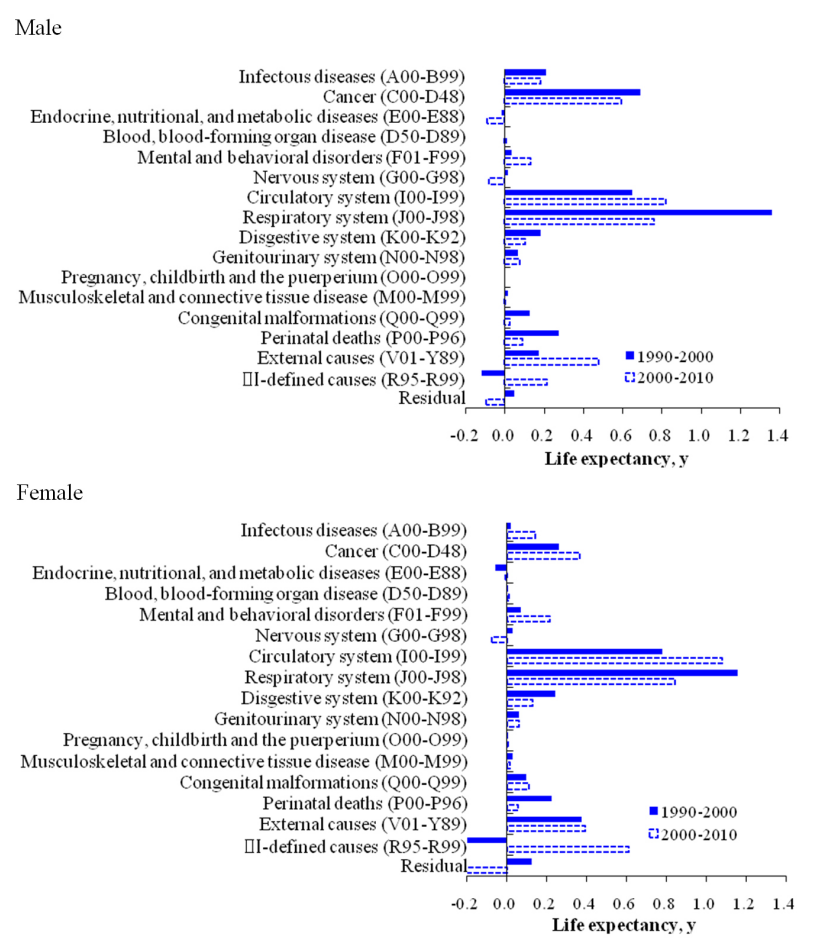

Figure 3. Disease group-specific contributions to life expectancy increase among males and females: Shanghai, 1990-2000 and 2000-2010
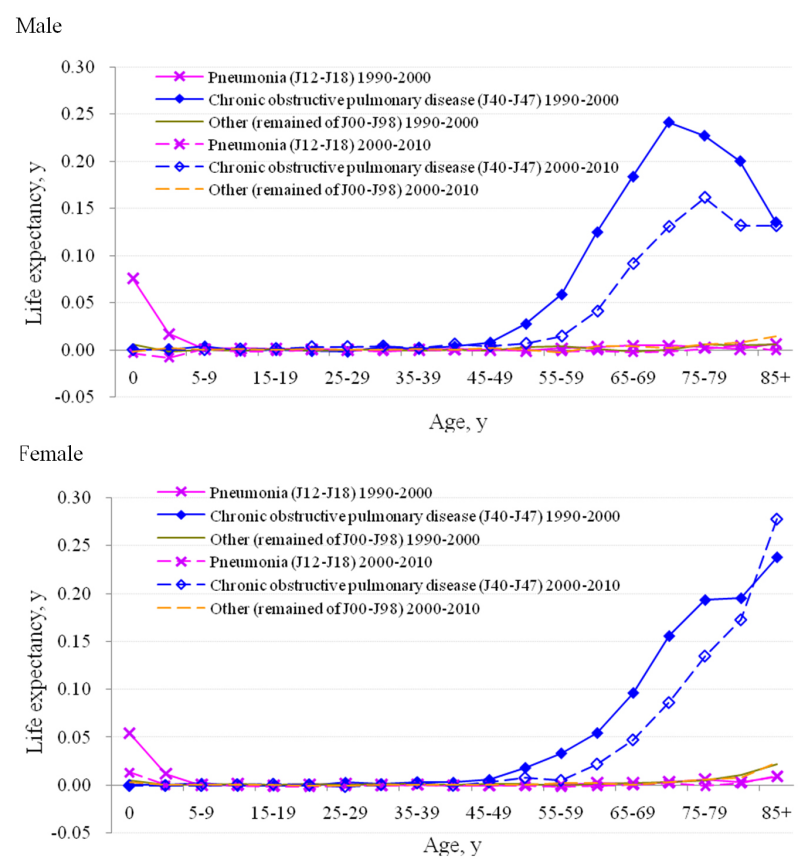

Figure 4. Age group-specific and disease group-specific contributions to life expectancy change caused by respiratory system among male and female: Shanghai, 1990-2000 and 2000-2010

\subsection{Contributions by specific diseases}

In order to know what kind of specific diseases contributed most to LE increases, contributions by subgroups of respiratory system diseases, circulatory system diseases and cancers were analyzed in the study.

1.36-year and 0.76-year increase to man LE were attributable to the decreased mortality of respiratory system diseases in the two decades respectively. The declined mortality of chronic obstructive pulmonary diseases (COPD, J40-J47) contributed 1.21-year (89.12\%) and 0.73-year (96.52\%) increase in the two decades respectively (see Figure 4$)$. The decreased mortality of pneumonia (J12-J18) in the youngest age group, which contributed 0.1-year increase to male LE, was noteworthy in 1990-2000. But in 2000-2010, it became very small. Contributions from subgroups of respiratory system diseases had similar patterns among women. Overall, 1.16year and 0.84-year increase to female LE were attributable to declined mortalities of respiratory system diseases in 19902000 and 2000-2010 respectively. The contributions from lower mortality of COPD were highest, which accounted for 1-year $(86.21 \%)$ and 0.77 -year $(91.67 \%)$ of the contributions from respiratory system diseases in 1990-2000 and 2000-2010 respectively. Most of the positive contributions occurred in women aged above 50 years. The decrease in pneumonia mortality contributed 0.05 -year increase to female LE, whereas the contribution became very small during 2000-2010.

Contributions of specific diseases in circulatory system across each age group were shown in Figure 5. 0.65-year and 0.82-year increase in male LE were attributable to the decline of circulatory system diseases (especially to cerebrovascular disease, CVD, I60-I69) during 1990-2000 and 2000-2010. The decline mortality of CVD contributed 0.52year and 0.76-year increases respectively in the two decades. Most of the contributions occurred in population aged above 60 years. The decline mortality of ischemic heart disease was very small especially in the first decade. As to women, 0.82-year and 1.08-year increase were attributable to circulatory system diseases respectively in the two periods. The contributions from lower mortality of CVD were more in women than in men. It increased 0.59-year and 0.99-year to women LE in the two periods. Something special in women was the increase mortality of ischemic heart disease in population above 80 years, which let female LE decrease more than 0.15 years in 2000-2010.

Between 1990 and 2010, reduction in mortality of cancer (all types) increased LE by 1.28-year to men and 0.63-year to women (see Figure 6). For men, reductions in stomach cancer (C16, 0.48-year), liver cancer (C22, 0.39-year) and lung and 
bronchial cancer (C33-C34, 0.28-year) contributed mostly. The declined mortality of stomach cancer most occurred in age between 55 and 80 years. The declined mortality of liver cancer most occurred in age between 50 and 75 years. And the declined mortality of lung and bronchial cancer most occurred in age between 55 and 75 years. But among ages above 75 years, the mortality of lung and bronchial cancer increased. In women, among malignant neoplastic diseases, the largest positive affects to LE was observed from stomach cancer (0.28-year) and liver cancer (0.21-year). Lung and bronchial cancer just attributed 0.03-year increase to the female LE.

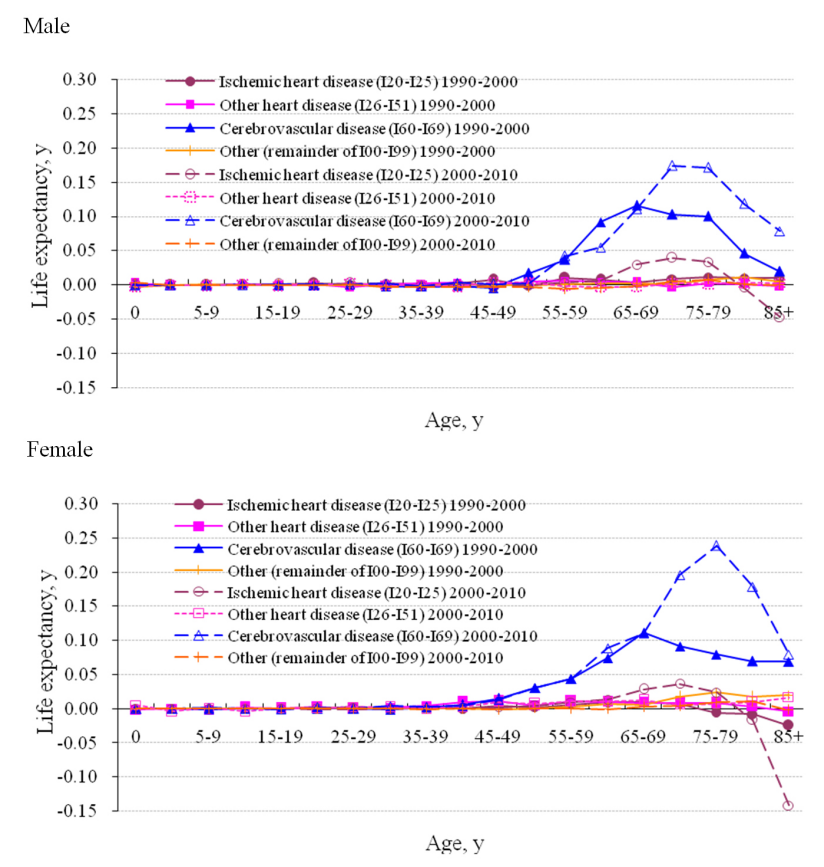

Figure 5. Age group-specific and disease group-specific contributions to life expectancy change caused by circulatory diseases among male and female: Shanghai, 1990-2000 and 2000-2010

The mortality rate of specific reason for accidental deaths had different change patterns. During 1990-2000, 0.17-year increase in male LE was mainly explained by the decrease in drowning (W65-W74, 0.13-year) and dropping (W10-W19, 0.09 -year). The effect of drowning mostly occurred in agegroup 1-9 years, and the effect of dropping mostly occurred in age-group above 55 years. These positive contributions were offset by rise in traffic accident (V01-V99, -0.14 years). During 2000-2010, external causes contributed 0.48-year increase to male LE. The decrease in drowning contributed 0.07-year increase in male LE. The decrease in dropping contributed 0.09-year increase in male LE. However, something different to the first decades was that the traffic accident had the positive contributions during the second period. The de- clined traffic accident contributed 0.18-year increased to life expectancy. In women, drowning and dropping had the similar patterns. The declined mortality of drowning contributed 0.09-year and 0.01-year to LE increase respectively in the two decades. The decline mortality of dropping contributed 0.14-year and 0.09-year to LE increase in the two periods. It was observed that the effect of drowning mostly occurred in girls aged under 5 years and the effect of dropping mostly occurred in women aged above 75 years. Something special to women was that the decrease of suicide contributed 0.11-year and 0.09-year increase to female LE in the two periods.

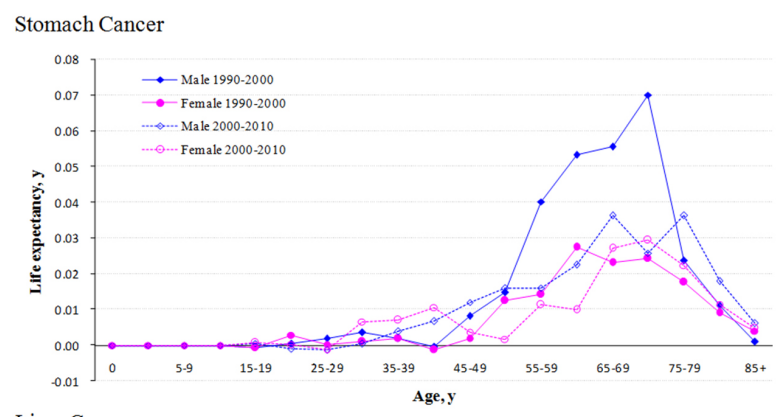

Liver Cancer

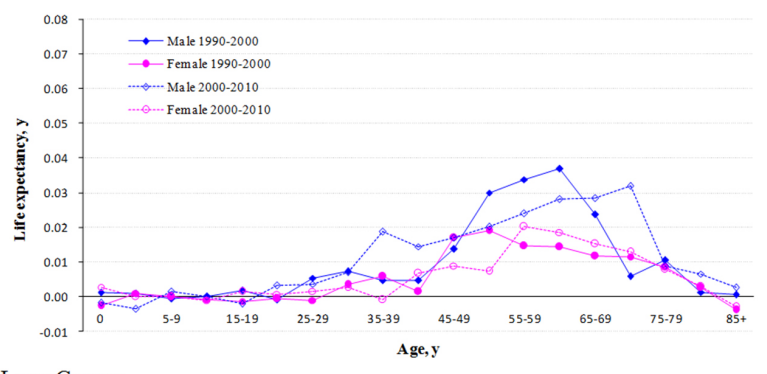

Lung Cancer

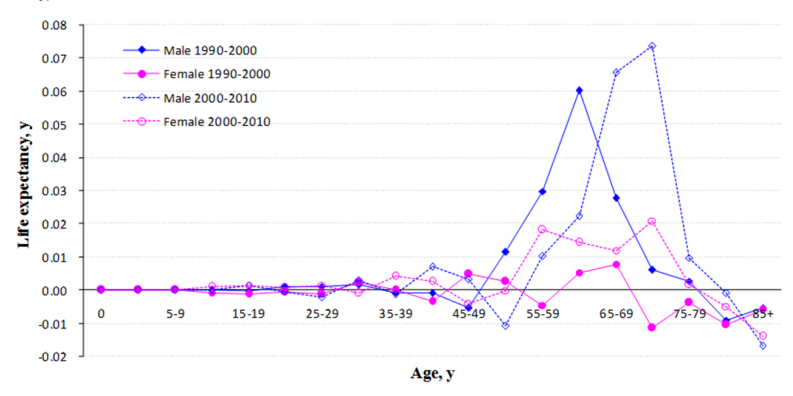

Figure 6. Age group-specific and disease group-specific contributions to life expectancy change caused by Cancer among male and female: Shanghai, 1990-2000 and 2000-2010

\section{Discussion}

Life expectancy at birth as a comprehensive method for measuring mortality had been used to reflect population's health status for a long time. Arriaga's decomposition method for mortality rates is commonly used in demography to analyze changes of LE. ${ }^{[1,5,7]}$ In this study, LE increase in Shanghai 
during 1990-2010 was disassembled as varying contributions from declining mortality in different age groups and diseases. LE in Shanghai increased very fast in the last two decades. In the first decade, decrease of infant mortality played an important role, however as aging in Shanghai became more and more critical, contributions from the decrease mortality of elderly population became more and more important. The study results showed that rapid increases in LE were mainly attained by declining mortality in aging population and chronic noncommunicable disease.

Life expectancy was critically influenced by infant mortality rate. In 1990, the infant mortality rate in Shanghai was 11 deaths per 1,000 births and dropped to 5 in 2000. In this study, it was consistent with results in other countries ${ }^{[6,7]}$ that reductions in infant mortality contributed most to age specific LE. Infant mortality in pneumonia, prematurity and low birth weight, birth asphyxia and birth trauma decreased in 19902000. Steady declines in fertility, comprehensive universal health insurance and the promotion of the national health policy, such as "World Declaration for the Survival, Protection and Development of Children" and "Chinese children's development program", may account for the extraordinary reduction in infant mortality. But when infant mortality is in very low level, life expectancy switches and depends primarily on the lifetimes of old people. So from 2000 to 2010, the falling speed of infant mortality rate was slow. And most of the infant deaths were caused by birth defects or preterm birth, which were caused by genetic and environmental factors and couldn't be avoid easily. ${ }^{[8]}$ The study showed that most of the increases of LE were owed to the old age, and most of the contributions lied in the decreasing mortality of respiratory system diseases (especially in COPD), circulatory system disease (especially in cerebrovascular disease), cancer (especially in stomach and liver cancer) and injuries.

Results in Global Burden of Disease Study in 2010 had shown that the Years of Life Lost of COPD had decreased 45\% form 1990 to 2010, although it didn't move down in rank. But stroke, ischemic heart disease and COPD were still the leading causes of death in China. ${ }^{[9]}$ And the incidence of COPD among subjects aged $\geq 60$ years in China was 2-3 times higher than those in other WHO regions. ${ }^{[10-12]}$ The downward trend of COPD may be driven mostly by the application of a variety of treatment and prevention measures in Shanghai. And relations might exist between exposure to respiratory infections as a child and adult COPD that can also alter secular trends. ${ }^{[13]}$ On the other hand, the largest production and consumption of tobacco had seen a striking increase over the past 2 decades in China and the peak of smoking-induced diseases is still to come. ${ }^{[14]}$ For instance, the UK and Australia also suggested that cause of death declined from 1900 to 1940 then increased until the 1980s from rising tobacco consumption. ${ }^{[15,16]}$ So it is very important to strengthen anti-smoking measures so as to have a far-reaching effect on the future health of the Chinese population.

Circulatory system diseases had been the most important cause of death in Shanghai for more than 10 years, although in the past two decades the reduced mortality in circulatory system diseases had done great contributions to the increases in LE. It was similar to findings from other countries, including Taiwan, ${ }^{[17]}$ Italy, ${ }^{[18]}$ Germany, ${ }^{[1]}$ and United States, ${ }^{[19]}$ but in Shanghai mortality of ischemic heart disease did not change radically as what occurred in other developed countries. The contributions of circulatory diseases was primarily owed to the decrease of cerebrovascular disease, similar to Japan $^{[20,21]}$ and Taiwan. ${ }^{[22]}$ In recent years, Shanghai government had adopted many effective policies to improve the levels of health status of the population, such as increasing physical activity, reducing sodium and oil intake, advocating balanced diet and so on. ${ }^{[23,24]}$ Even small reductions in these risks could generate substantial health benefits.

Despite enormous efforts to reduce cancer mortality, the success recently was not as much as we expected, nevertheless, substantial improvement in medical treatment and prognosis of some specific kinds of malignant tumor (i.e. stomach, liver and cervical cancers) were made. Being consistent with worldwide trends in mortality, this study shows a stable and continuous contribution from declined mortality in stomach cancer, ${ }^{[25]}$ especially in men. Stomach cancer mortality had decreased substantially in most parts of the world, in part due to the increased availability of fresh fruits and vegetables, and a decreased reliance on salted and preserved foods. Other major determinants for the favorable trends were reductions in Helicobacter pylori infections in most parts of the world. ${ }^{[26-30]}$ The morbidity of stomach cancer has been declining for several decades, but it is still one of the main causes of deaths in malignant tumor in Shanghai.

The declining mortality of liver cancer led to the raise of LE in both genders, especially in men. The epidemiological studies showed that liver cancer in China was mainly concerned with water pollution, aflatoxin intake, hepatitis virus infection and mother-to-infant transmission. ${ }^{[31]}$ In the early $70 \mathrm{~s}$, the Chinese government put forward many preventive measures, such as promoting tube water, preventing hepatitis, changing food etc. ${ }^{[32]}$ Shanghai was the first city which introduced free hepatitis b vaccine to the infant immunization schedules in China. After that, in the following decades, incidence of live cancer had a significantly reduced. ${ }^{[33]}$ But as the lifestyle changing, risk factors of liver cancer had a 
corresponding change. The factors above may be weaker and weaker. And other risk factors, such as obesity, diabetes, smoking, drinking and hepatitis $\mathrm{C}$ virus infection, are likely to increase gradually. ${ }^{[34]}$

Gains of LE attributed to decreases mortality of lung cancer were observed in men, but that were not shown in women, especially in the first decades. Potential gains of LE in women were shortened due to an increase mortality of lung cancer which reflected the variation in smoking behavior. ${ }^{[35,36]}$ The relatively high burden of lung cancer in females is thought to reflect air pollution, cooking fumes and second-hand smoke in China, ${ }^{[37-42]}$ and the sensitivity of female to lung cancer.

Mortality of transport injuries increased until 2000, possibly because of rapid industrialization. During 1979-1998, motor vehicle and motorcycle had increased 24.67 times and 199.98 times. Traffic accidents had become the first damage cause of death among urban residents in China. ${ }^{[43]}$ The accodent causes involved people, vehicles, roads and environment factors. Effective interventions on those risk factors will control the occurring of traffic accidents. In the beginning of 2000, in order to relief the rising traffic pressure, Shanghai government had put many effective measures into traffic improvement, such as improving urban roads, strengthening traffic managements and so on. And those measures had achieved a remarkable success. ${ }^{[4]}$ That may partly explain the negative contributions from traffic accidents during 1990-2000 and the positive contributions during 2000-2010.

With the change of the environment and people's lifestyle, although circulatory diseases, cancer and respiratory disease contributed mostly to the life expectancy both in males and females, those were still the main causes of death in now dates. Main causes of death, such as birth defects and most chronic noncommunicable diseases, are caused by a complex relationship of genetic factors, lifestyle (e.g. low physical activity, overweight, smoking, excessive salt intake, etc.) and socioeconomic status, ${ }^{[45-48]}$ so future efforts to increase life expectancy should aim at improvements in genetic research, healthy life style and the social environment.

\section{REFERENCES}

[1] Klenk J, Rapp K, Büchele G, et al. Increasing life expectancy in Germany: quantitative contributions from changes in age- and disease-specific mortality. Eur J Public Health. 2007; 7(6): 587-92. http://dx.doi.org/10.1093/eurpub/ckm024

[2] United Nations. World Mortality Report 2005. New York, 2006.

[3] Arriaga EE. Measuring and explaining the change in life expectancies. Demography. 1984; 21(1): 83-96. http://dx.doi.org/10 $2307 / 2061029$

[4] Arriaga EE. Changing trends in mortality declined during the last decades. In: Ruzicka LT, Wunsch GJ, Kane P, eds. Deferential mortality: Methodological Issues and Biosocial Factor. Oxford, England: Claredon Press; 1989. p. 105-29.

[5] Shkolnikov V, McKee M, Leon DA. Changes in life expectancy in Russia in the mid-1990s. Lancet. 2001; 357: 917-21. http: //dx.doi.org/10.1016/S0140-6736(00)04212-4

[6] Yang S, Khang YH, Harper S, et al. Understanding the rapid increase in life expectancy in South Korea. American Journal of Public Health. 2010; 100(5): 896-903. PMid:20299661. http: //dx.doi.org/10.2105/AJPH. 2009. 160341

[7] McGuire JW. Social policy and mortality decline in East Asia and Latin America. World Dev. 2001; 29(10): 1673-97. http: //dx.doi.org/10.1016/S0305-750X (01)00062-6

[8] Vinceti M, Malagoli C, Teggi S, et al. Adverse pregnancy outcomes in a population exposed to the emissions of a municipal waste incinerator. Science of the total environment. 2008; 407: 116-21. http://dx.doi.org/10.1016/j.scitotenv.2008.08.027

[9] Yang G, Wang Y, Zeng YX, et al. Rapid health transition in China, 1990-2010: finds from the Global Burden of Disease Study 2010. Lancet. 2013; 381: 1987-2015.

[10] Murray CJL, Lopez AD. Alternative projections of mortality and disability by cause 1990-2020: Global burden of disease study. Lancet.
1997; 349: 1498-1504. http://dx.doi.org/10.1016/S0140-6 736 (96) $07492-2$

[11] Lopez AD, Shibuya K, Rao C, et al. Chronic obstructive pulmonary disease: current burden and future projections. Eur Respir J. 2006; 27: 397-412. PMid:16452599. http://dx.doi.org/10.1183/0 9031936.06 .00025805

[12] Mannino DM, Kiri VA. Changing the burden of COPD mortality. International Journal of COPD. 2006; 1(3): 219-33. PMid:18046859.

[13] Hurley SF, Matthews JP. The Quit Benefits Model: a Markov model for assessing the health benefits and health care cost savings of quitting smoking. Cost Eff Resour Alloc. 2007; 5: 2. PMid:17241477. http://dx.doi.org/10.1186/1478-7547-5-2

[14] Zhang H, Cai BQ. The impact of tobacco on lung health in China. Respirology. 2003; 8: 17-21. PMid:12856737. http://dx.doi.o $\mathrm{rg} / 10.1046 / \mathrm{j} .1440-1843.2003 .00433 . \mathrm{x}$

[15] Logan WPD. Mortality in England and Wales from 1848 to 1947. Popul Stud. 1950; 4: 132-78. http://dx.doi .org/10.2307/217 2133

[16] Adair T, Hoy D, Dettrick Z, et al. 100 years of Chronic Obstructive Pulmonary Disease (COPD) mortality in Australia: the role of tobacco consumption. Int J Tuberc Lung Dis. 2012; 16: 1699705. PMid:23131272. http://dx.doi.org/10.5588/ijtld. 12 . 0251

[17] Wen CP, Tsai SP, Chung WS. A 10-year experience with iniversal health insurance in Taiwan: measuring changes in health and health disparity. Ann Inter Med. 2008; 148(4): 258-67. http: //dx.doi.o rg/10.7326/0003-4819-148-4-200802190-00004

[18] Conti S, Farchi G, Masocco M, et al. The impact of the major causes of death on life expectancy in Italy. Int J Epidemiol. 1999; 28: 90510.

[19] Gomez-Redondo R, Boe C. Decomposition analysis of Spanish life expectancy at birth: evolution and changes in components by sex and 
age. Demogr Res. 2005; 13: 521-46. http://dx.doi.org/10.40 54/DemRes . 2005.13.20

[20] Watanabe T, Omori M, Fukuda H, et al. Influence of death from circulatory diseases on life expectancy at birth in Japan. J Epidemiol. 2002; 12: 450-6.

[21] Yoshinaga K, Une H. Contributions of mortality changes by age group and selected causes of death to increase in Japanese life expectancy at birth from 1950 to 2000. Eur J Epidemiol. 2005; 20: 4957. PMid:15756904. http://dx.doi.org/10.1007/s10654-0 04-9557-x

[22] Chang CC, Chen CJ. Secular trend of mortality from cerebral infarction and cerebral hemorrhage in Taiwan, 1974-1988. Stroke. 1993: 212-8. PMid:8421821.

[23] Lv N, Li XJ, Zheng Y, et al. An analysis of incidence rate of stroke in monitored population of Shanghai from 1999 to 2001. Chin Prev Med. 2002; 3(4): 271-4.

[24] Hong Y, Bots ML, Pan X, et al. Stroke incidence and mortality in rural and urban Shanghai from 1984 through 1991. Findings from a community-based registry. Stroke. 1994; 25: 1165-9. PMid:8202974. http://dx.doi.org/10.1161/01.STR.25.6.1165

[25] Levi F, Lucchini F, Gonzalez JR, et al. Monitoring falls in gastric cancer mortality in Europe. Ann Oncol. 2004; 15: 338-45.

[26] Bertuccio P, Chatenoud L, Levi F, et al. Recent patterns in gastric cancer: a global overview. Int J Cancer. 2009; 125: 666-73. PMid:19382179. http://dx.doi.org/10.1002/ijc. 24290

[27] Ahmedin J, Freddie B, Melissa M, et al. Global Cancer Statistics. CA Cancer J Clin. 2011; 61: 69-90. PMid:21296855. http: //dx.doi.org/10.3322/caac. 20107

[28] Chen J, Bu XL, Wang QY, et al. Decreasing seroprevalence of Helicobacter pylori infection during 1993-2003 in Guangzhou, southern China. Helicobacter. 2007; 12: 164-9. PMid:17309754. http: //dx.doi.org/10.1111/j.1523-5378.2007.00487.x

[29] Fischbach W, Chan AO, Wong BC. Helicobacter pylori and Gastric Malignancy. Helicobacter. 2005; 10(1): 34-9. PMid:16178969. http://dx.doi.org/10.1111/j.1523-5378.2005.00338.x

[30] Adami HO, Hunter D, Trichopoulos D. Cancer epidemiology. Oxford: Oxford University Press; 2002.

[31] Blaser MJ, Nomura A, Lee J, et al. Early-life family structure and microbially induced cancer risk. PLoS Med. 2007; 4(1): e7. PMid:17227131. http://dx.doi.org/10.1371/journal.pme d. 0040007

[32] Chang MH, You SL, Chen CJ, et al. Decreased incidence of hepatocellular carcinoma in hepatitis B vaccinees: a 20-year follow-up study. J Natl Cancer Inst. 2009; 101: 1348-55. PMid:19759364. http://dx.doi.org/10.1093/jnci/djp288

[33] Gao S, Yang WS, Bray F, et al. Declining rates of hepatocellular carcinoma in urban Shanghai: incidence trends in 1976-2005. Eur J Epidemiol. 2011; 27(1): 39-46.
[34] Liang X, Bi S, Yang W, et al. Epidemiological serosurvey of hepatitis B in China-declining HBV prevalence due to hepatitis B vaccination. Vaccine. 2009; 27(47): 6550-7. PMid:19729084. http://dx.doi.org/10.1016/j.vaccine. 2009.08.048

[35] Yang G, Ma JM, Liu N, et al. Smoking and passive smoking in Chinese, 2002. Chinese Journal of Epidemiology. 2005; 26(2): 77-83. PMid:15921604.

[36] Xu JY, Chen T, Wu F, et al. A Cross sectional survey of tobacco control in Shanghai, 2010. J Environ Occup Med. 2012; 29(10): 612-5.

[37] Lam WK, White NW, Chan-Yeung MM. Lung cancer epidemiology and risk factors in Asia and Africa. Int J Tuberc Lung Dis. 2004; 8 : 1045-57. PMid: 15455588.

[38] Ezzati M, Lopez AD. Estimates of global mortality attributable to smoking in 2000. Lancet. 2003; 362: 847-52. http://dx. doi .org $/ 10.1016 / \mathrm{S} 0140-6736$ (03) 14338-3

[39] Youlden DR, Cramb SM, Baade PD. The International Epidemiology of Lung Cancer: geographical distribution and secular trends. J Thorac Oncol. 2008; 3: 819-31. PMid:18670299. http://dx. doi . org/10.1097/JTO.0b013e31818020eb

[40] Ezzati M, Lopez AD. Estimates of global mortality attributable to smoking in 2000. Lancet. 2003; 362: 847-52. http://dx. doi .org $/ 10.1016 / \mathrm{S} 0140-6736$ (03) $14338-3$

[41] Boffetta P, Nyberg F. Contribution of environmental factors to cancer risk. Br Med Bull. 2003; 68: 71-94. PMid:14757710. http: //dx.doi.org/10.1093/bmp/ldg023

[42] Thun MJ, Hannan LM, Adams-Campbell LL, et al. Lung cancer occurrence in never smokers: an analysis of 13 cohorts and 22 cancer registry studies. PLoS Med. 2008; 5: e185.

[43] CHI GB, WANG SY. Secular trend and determinant of road injury in China (1949-1998)(in chinese). Chin J Traumatol. 2000; 16(4): 202-3.

[44] ZHOU F, ZHOU SF, YANG BJ, et al. Analysis of Motor Vehicle Traffic Accidents in Shanghai during the Period of 2002-2007. J Environ Occup Med. 2009; 26(3): 259-62.

[45] Tang YW, et al. The Risk of Birth Defects in Multiple Births: A Population-Based Study. Maternal and Child Health Journal. 2006; 10(1): 75-81.

[46] Meherg A, Lindherg H, Thaulow E. Congenital heart defects: the patients who die. Acta Paediatr. 2005; 94: 1060-5. PMid:16188850. http://dx.doi.org/10.1080/08035250410025618

[47] Willett WC. Balancing lifestyle and genomics research for disease prevention. Science. 2002; 296: 695-8. PMid:11976443. http: //dx.doi.org/10.1126/science.1071055

[48] Ezzati M, Lopez AD, Rodegers A, et al. Selected major risk factors and global and regional burden of disease. Lancet. 2002; 360: 1347-60. 